\title{
MOBILITY IMPAIRMENT IN THE ELDERLY: CHALLENGES FOR BIOMECHANICS RESEARCH
}

\author{
Albert B. SChultz \\ Department of Mechanical Engineering and Applied Mechanics, University of Michigan, Ann Arbor, \\ MI 48109-2125, U.S.A.
}

\begin{abstract}
The problems of mobility impairment in the elderly constitute new and major challenges for biomechanics research. This paper outlines what some of the important problems are, discusses the relevance of biomechanics research to these problems, and reviews some of the current state of knowledge about factors related to the biomechanics of mobility impairments in the elderly. The population of old adults is growing rapidly and the incidence of mobility impairments in old adults is high. Mobility impairment biomechanics research is needed to make the assessments of impairments more precise, to design therapeutic programs that are more effective and to learn more about how mobility impairments can be prevented.
\end{abstract}

\section{THE MAGNITUDE OF THE CHALLENGES}

The population of elderly adults is a growing one; life expectancy continues to increase. In the United States, mean life expectancy at birth for females was $49.1 \mathrm{yr}$ in $1900,77.5 \mathrm{yr}$ in 1980 , and is projected to be $82.2 \mathrm{yr}$ in 2020 . The corresponding figures for males are 46.6, 69.8 and 74.4 yr (Olshansky and Ault, 1986). In 1986, there were 29.2 million residents of the United States who were 65 or more years old and 2.8 million residents who were 85 or more years old (Public Health Service, 1989a). If projected conservatively, these numbers will grow to 52 million and 6.7 million by the year 2020 (Schneider and Guralnik, 1990).

What will be the quality of these additional years of life? Will they be years of freedom and personal fulfillment or years of confinement and dependence? Maintenance of mobility is central to this issue. For example, the risk of hip fracture increases dramatically after age 50 , and almost $50 \%$ of hip fractures occur in persons who are 80 or more years old. In 1987, approximately 220,000 hip fractures occurred in the United States. This number will grow to over 400,000 by the year 2020 . Approximately $20 \%$ of women who experience a hip fracture do not survive the first year after the fracture. Another $20 \%$ do not regain the ability to walk without assistance (Schneider and Guralnik, 1990). The inability to walk without assistance often leads to institutionalization.

What will be the costs to society of these additional years of life? The costs for nursing home care of the elderly in 1985 averaged $\$ 23,600$ per resident and totalled \$31.1 billion (Schneider and Guralnik, 1990). The number of nursing home residents is projected to increase 3.5 fold by 2040 (Olshansky and Ault, 1986). The costs of hip fractures, which were approximately $\$ 1.6$ billion in 1987 , are projected to be $\$ 6$ billion by 2040 (Schneider and Guralnik, 1990).

Received in final form 6 August 1991.

\section{THE RELEVANCE OF BIOMECHANICS RESEARCH}

Physical-task performance requires that the masses and inertias of body segments be supported and moved by the skeletal system through its muscular actions. Changes in cognition and central nervous system processing; changes in visual, vestibular and proprioceptive sensing abilities; the effects of physical inactivity and disuse; the effects of neurologic and musculoskeletal pathologies; the effects of medications; and the effects of motivation and fear all ultimately express themselves as changes in the biomechanics of physical-task performance.

Research on the biomechanics of mobility impairment in the elderly is needed to quantify impairment magnitudes, to determine what elements are critical to these impairments, to improve therapies for remediation and to design more effective programs for their prevention. Current evaluations of impairments are largely qualitative. Biomechanical measurements that quantify mobility impairments need to be devised to define more carefully the levels of functioning in cross-sectional studies and to serve as more precise outcome measures in studies of the effects of therapeutic interventions. Of more importance is the fact that qualitative measures of impairment serve poorly, if at all, as indicators of subtle changes in functioning over time, yet there are major needs to understand these changes.

One of the most important goals for biomechanics research in this context is to find what the critical elements of a mobility impairment are. The widespread occurrence of gait impairments in the elderly will be documented subsequently. Many elements are involved in the ability to walk: joint ranges of motion. joint torque strengths, muscle latency times, musclesequencing programs, joint and cutaneous proprioception, control of balance and planning of movements, to name just a few. Are all these elements involved in every age-related gait impairment? How can a gait impairment be remedied if it is not known 
which of these elements have major responsibilities for the impairment? The need for biomechanics research into questions like these requires little explanation.

Physical therapy is sometimes prescribed for old adults with mobility impairments. This therapy is sometimes directed at increasing the muscular strength. However, biomechanical analyses show that the strength requirements for the maintenance of balance (Chun et al., 1992; Gu et al., 1992) and even those for rising from a chair (Schultz et al., 1991) are usually smaller and, in the former case, considerably smaller than the available strengths in even quite old adults. Might other forms of therapy be more appropriate for at least some impairments? Balance training, for example, might be more effective than strength training in remediation of balance problems. Ledin $e t$ al. (1991) demonstrated that nine weeks of balance training significantly improved the balance abilities in persons $70-75 \mathrm{yr}$ old. Therapies and programs for the prevention of impairments can be made more effective once a better understanding is achieved of the specific factors which are important for the restoration and maintenance of a given function. Biomechanics research is likely to contribute to this understanding.

\section{AGE EFFECTS ON MUSCULOSKELETAL SYSTEM COMPONENTS}

This and the subsequent sections of this paper will review representative studies of functional decline with age in the performance of physical tasks. Studies of functional decline with age should be interpreted with caution. Their outcome often depends critically on subject inclusion criteria. Unless these are quite stringent and clearly explained, it is difficult to separate the effects of natural aging from the effects of disease processes, medication, and the state of physical fitness, for example.

\section{Anthropometry}

The anthropometry of the elderly differs somewhat from that of young adults (Ward and Kirk, 1967; Burr and Phillips, 1984; Shimokata et al., 1989; Kelly and Kroemer, 1990, for example). Stoudt (1981) points out that in the mean, persons $65-74$ yr old are approximately $3 \%$ shorter than those $18-24$ yr old. Elderly males are slightly lighter and elderly females approximately $11 \%$ heavier than young adult males and females. These differences result from both secular trends in the population and biological changes inherent in the aging process. In illustration of the latter factor, most of the decrement in stature takes place in the trunk and results from a flattening of the intervertebral disks and vertebral bodies and changes in kyphosis.

\section{Joint ranges of motion}

The ranges of motion (ROM) of body joints generally diminish with age. For example, Allander $e t$ al.
(1974) reported an approximately $20 \%$ decline between ages 45 and $70 \mathrm{yr}$, among 411 subjects, in hip rotation and $10 \%$ declines in wrist and shoulder ROM. A comparison of the ROM of lower extremity joints reported by Boone and Azen (1979) and Roaas and Andersson (1982) for young and middle-aged adults with those reported by Walker et al. (1984) for elderly adults shows declines ranging from negligible to $57 \%$. Svanborg (1988) found that at age 79 , onefifth of a large group of subjects had restricted knee joint motion and two-thirds had restricted hip joint motion. Battie et al. (1987), in 3020 blue-collar workers, found an approximately $25 \%$ decline in the ability to bend to the side and a $45 \%$ decline in shoulder motion over the ages of $20-60 \mathrm{yr}$. Einkauf et al. (1987), in 109 healthy females, found declines of $25-50 \%$ in various ranges of motion of the lumbar spine over ages of approximately $20-80 \mathrm{yr}$. However, Walker et al. (1984) reported no significant differences in 28 different joint ROM between two groups with mean ages of approximately 65 and $80 \mathrm{yr}$.

The effects of decreased ROM on the ability to perform various activities of daily living are less well studied, not only in old but even in young adults. Badley et al. (1984) found, when studying 95 subjects of ages 28-84 yr with arthritis, that the ability to move around in one's environment correlated significantly with ROM in knee flexion, the ability to bend down correlated with hip flexion ROM, and the ability for activities requiring the use of hands and arms correlated significantly with ROM of the upper extremities. Bergstrom et al. (1985a) reported that restricted knee motion in $79 \mathrm{yr}$ olds correlated with the disability to enter public transport vehicles. However, they found that joint impairment did not generally associate with commitment to institutional care. Bergstrom et al. (1985b) found that the majority of a group of 134 people of age $79 \mathrm{yr}$ had enough spinal mobility to perform the common activities of daily living. Biomechanics research further detailing the relationships between decreased ROM and mobility impairments seems merited.

\section{Muscle function}

The decline in the muscle strength that accompanies aging has long been recognized (Quetelet, 1835; Cathcart et al., 1935, for example). The order of magnitude of this decline, say between ages 25 and 65 , is onethird. However, precise strength values reported vary widely because they depend on many factors: for example, they depend very substantially on the subjects studied, the joint angles, whether under isometric or constant-velocity conditions, and whether, at the constant velocity, muscle shortening or lengthening is occurring. Table 1 provides typical literature data on extremity joint muscle strengths for young and old adults. Viitisalo et al. (1985) report that hand grip, elbow flexion and trunk flexion and extension strengths decline $35-45 \%$ between the early thirties and the early seventies. Vandervoort et al. (1990) 
Table 1. Literature values for joint torque strengths $(\mathrm{N} \mathrm{m})^{*}$

\begin{tabular}{|c|c|c|c|c|}
\hline \multirow[b]{2}{*}{ Data source } & \multicolumn{2}{|c|}{ Young adults $\uparrow$} & \multicolumn{2}{|c|}{ Old adults $\ddagger$} \\
\hline & Females & Males & Females & Males \\
\hline \multicolumn{5}{|l|}{ Ankle dorsiflexors } \\
\hline $\begin{array}{l}\text { Oberg et al. } \\
\text { Sepic et al. }\end{array}$ & $\begin{array}{l}49 \\
44\end{array}$ & 78 & 46 & 74 \\
\hline \multicolumn{5}{|l|}{ Ankle plantarflexors } \\
\hline Oberg et al. & 188 & & & \\
\hline Gerdle and Fugl-Meyer & & & 78 & 139 \\
\hline Falkel & 58 & 87 & & \\
\hline Sepic et al. & 100 & 129 & 82 & 131 \\
\hline \multicolumn{5}{|l|}{ Knee flexors } \\
\hline Knapic et al. & 87 & 195 & & \\
\hline Borges & 100 & 155 & 65 & 109 \\
\hline Murray et al. & 78 & & 50 & \\
\hline \multicolumn{5}{|l|}{ Knee extensors } \\
\hline Knapic et al. & 160 & 250 & & \\
\hline Dannenskiold et al. & & & 75 & 120 \\
\hline Aniansson et al. & & & 108 & 191 \\
\hline Borges & 183 & 289 & 128 & 188 \\
\hline Murray et al. & 176 & & 110 & \\
\hline \multicolumn{5}{|l|}{ Hip flexors } \\
\hline Markhede and Grimby & & 120 & & \\
\hline Cahalan et al. & 66 & 108 & 51 & 89 \\
\hline \multicolumn{5}{|l|}{ Hip extensors } \\
\hline Markhede and Grimby & & 248 & & \\
\hline Cahalan et al. & 126 & 204 & 110 & 203 \\
\hline \multicolumn{5}{|l|}{ Shoulder flexors } \\
\hline Murray et al. & 50 & 104 & 38 & 84 \\
\hline \multicolumn{5}{|l|}{ Shoulder extensors } \\
\hline Murray et al. & 53 & 80 & 35 & 74 \\
\hline
\end{tabular}

* Adapted from Schultz et al. (1991). Data sources are cited in that paper. Most values quoted are for isometric strengths, but a few are for low-rate isokinetic strengths.

+ Mean ages approximately $25-30 \mathrm{yr}$, see references.

$\ddagger$ Mean ages approximately $60-80 \mathrm{yr}$, see references.

report age differences in strength to be smaller when muscles lengthen than when they shorten.

A prevalent casual belief is that many of the mobility impairments that arise in the elderly are due to a decline in the muscular strength. This belief warrants careful consideration. Studies were cited above suggesting that the joint torques needed to maintain postural balance and even to rise from a chair are often well below the available joint torque strengths. Further, comprehensive biomechanical studies are needed of the muscle strength requirements for all common activities of daily living in order to relate the strength requirements, strength availabilities and performance in these activities.

The decline with aging in the ability of muscles to produce power is perhaps well illustrated by records of peak athletic performances. Moore (1975), in his study of age effects in record running performance, shows that in both short- and long-distance races, male elite runners over $70 \mathrm{yr}$ old run one-third slower than elite young adult male athletes (Fig. 1). The latter tend to be in their twenties. In their review of muscle function with age, Faulkner et al. (1990) point out that rodent muscle power outputs decline approximately $30 \%$ in

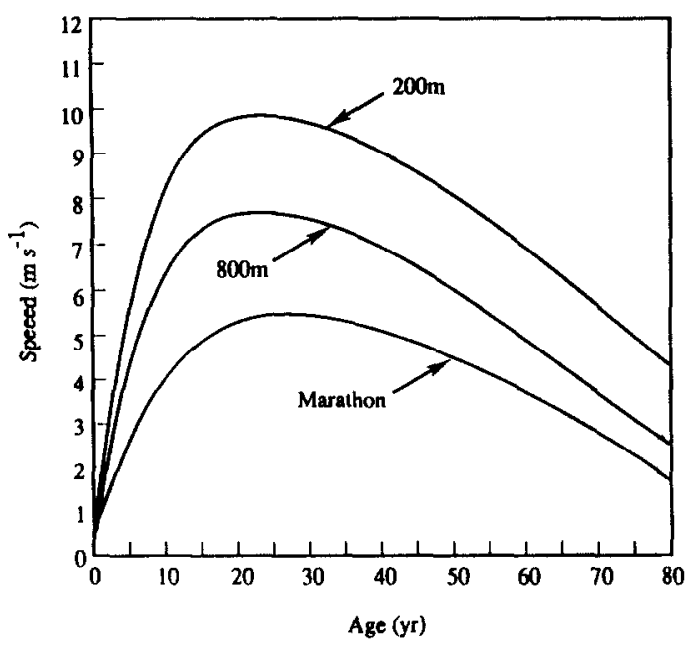

Fig. 1. Age effects in world record running speeds. Data from Moore (1975).

absolute terms and $20 \%$ on a per unit muscle mass basis. Age-related changes in muscle morphology and physiology have been reviewed by Grimby and Saltin (1983) and Faulkner et al. (1990), for example. The 
latter concluded that the maximum speed of shortening, contraction times and fiber types do not seem to change significantly with aging, but fast/slow fiber innervation ratios do seem to. Muscle power reduction with aging may also be due to systemic factors, such as decline in cardiopulmonary function (Gorman and Posner, 1988).

A number of studies suggest that exercise in later years can help maintain muscular strength (review of Shepard, 1990, for example) and improve factors which indirectly influence muscle function (Gorman and Posner, 1988, for example). However, Block et al. (1989) point out that studies of this kind have sometimes yielded conflicting results and have sometimes been marred by methodological flaws, such as failure to use a randomized study design, failure to assess outcomes blindly and too short a study duration.

\section{Reaction times}

Reaction times, the delays that occur between the onset of a stimulus and the onset of response to it, are of fundamental importance to biomechanical analyses of any tasks performed rapidly. Reaction times are often categorized into simple (SRT) and choice (CRT) reaction times, the latter involving selection among several possible response options and, thus, presumably involving more central processing of motor commands. Reaction times are further divided into premotor times, from stimulus onset to the onset of myoelectric activity, and motor times, from the onset of myoelectric activity to the onset of force production or movement. Usually, the main issue in the studies of the slowing down of performance with age has been the extent to which the slowing down results from 'central' mechanisms in contrast to 'neuromuscular mechanisms' (for example, Welford, 1984, 1988). CRT are thought to associate more with the former and SRT more with the latter. Thus, Rogers and Chan (1988) interpreted their findings, that patients with Parkinson's disease did not differ significantly from control subjects in their SRT but did differ in their CRT, as suggesting that parkinsonian akinesia may involve a disturbance in the central processing related to motor planning.

The data Welford $(1984,1988)$ reviewed suggest that SRT of old adults are approximately $20 \%$ longer than those of young adults. Salthouse (1985) reviewed 11 studies of the effects of age on SRT. Uniformly, age and reaction time show a positive linear correlation, but the correlation coefficients ranged from only 0.19-0.47. Gottsdanker (1982) found SRT to increase with age at a rate of only $2 \mathrm{~ms}$ per decade. A number of studies suggest that higher levels of physical fitness associate with shorter reaction times (Era et al., 1986, for example), but Clarkson (1978), for example, found such effects to be rather weak. The fitness level affected the time needed to make movements more than it affected the reaction time.

The lack of precise definitions, the lack of standards for experimental methods and the frequent use of test conditions that are biomechanically complex make data on reaction times sometimes difficult to interpret for the purposes of biomechanical analyses of rapid task performances. For example, Welford's (1984) review article tabulates mean simple premotor times in young adults that range from 109-255 ms. More data on age effects in SRT when attempts are made to move only single body joints are needed. Studies of the effects of different SRT on the ability to perform complex tasks rapidly are also needed. These probably can be conducted only through the use of direct dynamics biomechanical simulation models suited for 'what-if' parameter studies.

\section{Proprioception}

Relatively few studies have examined the changes in proprioception with aging (Stelmach and Worringham, 1985). Skinner et al. (1984) found joint position sense in the knee to deteriorate with age in their study of 29 subjects over a 62 yr age span. In approximate terms, joint angles could be reproduced to within $2^{\circ}$ by $20 \mathrm{yr}$ olds, but only to within $6^{\circ}$ by $80 \mathrm{yr}$ olds. Twentyyear olds could detect passive joint motions of $4^{\circ}$, but $80 \mathrm{yr}$ olds could detect only motions larger than $7^{\circ}$. Kokmen et al. (1978) compared joint motion sensation in 52 subjects over 60 yr old with that in 10 young adult subjects. In contrast to the findings of Skinner $e t$ al., they found no major decline with age in motion perception in finger and toe joints. Kokmen et al. (1977), examining 51 old adults who were active and self-declared as neurologically normal, confirmed a previously reported decline of vibration perception with aging.

\section{MOBILITY IMPAIRMENTS}

\section{Epidemiology of mobility impairments in the elderly}

Leon and Lair (1990) examined the functional status of non-institutionalized persons $65 \mathrm{yr}$ and older using data from the 1987 National Medical Expenditure Survey. The deterioration in functional status was measured in terms of the difficulty encountered in walking and in performing activities of daily living (ADL). ADL include performances other than walking that are essential for self-care, such as bathing, dressing, feeding oneself and toileting. Of the 27.9 million elderly persons in the United States, 3.6 million $(12.9 \%)$ had difficulty with at least one of these tasks. Difficulty with bathing affected 2.5 million (8.9\%), difficulty with walking, 2.2 million (7.7\%) and difficulty with bed or chair transfers, 1.6 million $(5.9 \%)$. The rate of problems increases progressively after age 65 , rising sharply in the eighties to reach $34.5 \%$ in noninstitutionalized persons 85 yr or older (Fig. 2). At all the ages studied, females had higher rates of ADL limitations than did males. Jette and Branch (1981) found that, of persons $75-84 \mathrm{yr}$ old, $23 \%$ have difficulty in walking one-half mile, $24 \%$ have difficulty 


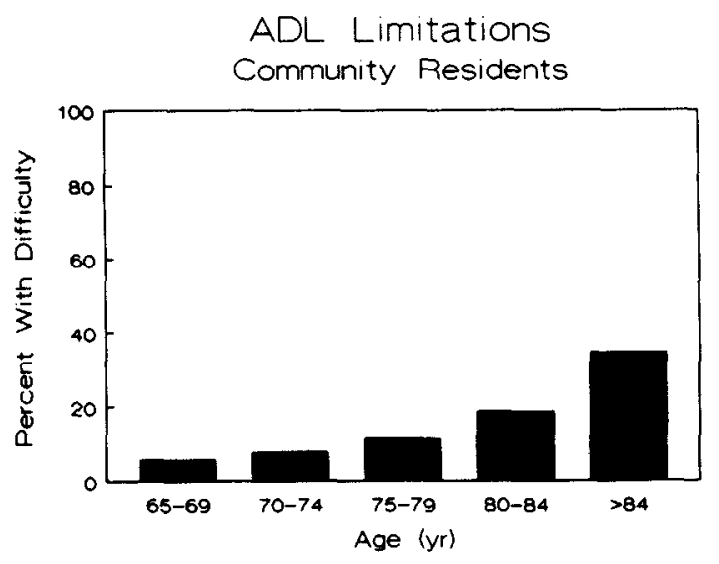

Fig. 2. Percentage of community-dwelling residents 65 or more years old who have difficulty with at least one activity of daily living. Data for 1987 (Leon and Lair, 1990).

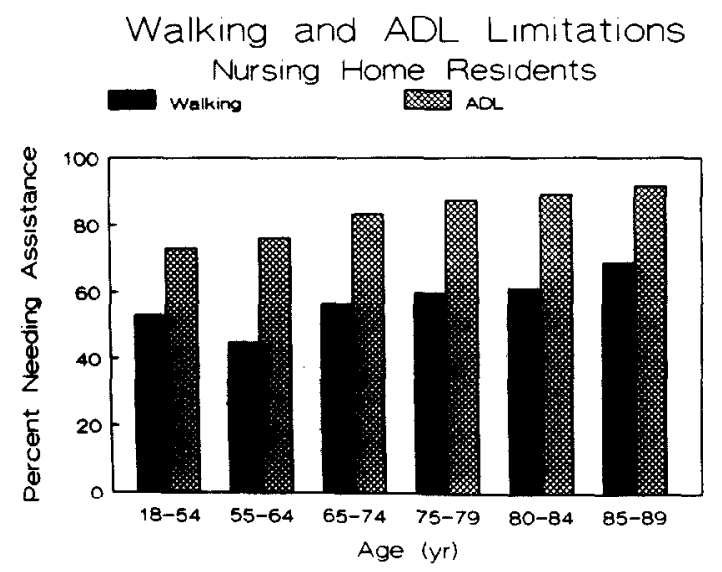

Fig. 3. Percentage of nursing home residents who require personal assistance with walking or at least one activity of daily living. Data for 1987 (Lair and Lefkowitz, 1990).

lifting a weight of less than $10 \mathrm{lb}$ and $55 \%$ have difficulty in stooping, crouching or kneeling.

Increasing levels of $A D L$ impairment often lead to institutionalization. Lair and Lefkowitz (1990) report that at least $56 \%$ of nursing home residents older than $64 \mathrm{yr}$ need personal assistance in walking and at least $83 \%$ need personal assistance with one or more ADL. For residents older than 84 yr these numbers become 69 and $92 \%$ respectively (Fig. 3).

\section{Evaluation of mobility impairments in the elderly}

Impairments are anatomical or physiological abnormalities of the body; disabilities are declines in an individual's functional performance, including physical and social performance. Jette and Branch (1985) found musculoskeletal and visual impairments to be strongly related to physical, but not to social, disability in the elderly.

Biomechanics research is needed to improve the evaluations of mobility impairments in the elderly. Guralnik et al. (1989) point out that physical-function levels have generally been assessed through self- or proxy-report and that measures of physical performance are needed to supplement these. Tinetti (1986) notes that locomotor, sensory and cognitive functioning are each intimately related to mobility. Assessments of function in the elderly have often relied solely on a disease-oriented approach. Clinically practical, performance-oriented assessments of mobility are also needed. Tinetti and Ginter (1988) found that currently used neuromuscular examinations for identifying mobility problems are not adequately able to identify these problems and that systematic evaluations of position changes and balance maneuvers are needed to identify specific problems. Potvin et al. (1981) present a comprehensive review of quantitative methods for the assessment of neurological function. Feinstein et al. (1986) critically review 43 different indices of $\mathrm{ADL}$ performance that are in current use and point out some of the problems in the construction of meaningful indices of this kind.

These and other authors outline the needs to better quantify the degree of impairment, largely for purposes of clinical evaluations of patient status. A more fundamental rationale for quantifying impairments in biomechanical terms was given in the second section of this paper: one of the most important goals for biomechanics research in the present context is to find which elements of a mobility impairment are the critical ones. Quantifying impairments in biomechanical terms is a major requirement for the success of this search.

\section{Postural balance}

Many studies of age effects in the ability to maintain postural balance have been reported. Horak et al. (1989) in a recent review of this topic pointed to the ample evidence of deterioration in many sensorimotor systems underlying postural control, even in elderly populations without obvious signs of disease. They concluded, however, that aging alone cannot account for the heterogeneity of postural control problems in the elderly. Winter et al. (1990) noted that responses to postural perturbations are task- and perturbationspecific, so that a single assessment technique cannot serve as a true indicator of the overall integrity of the balance control system.

Reports of age effects on sway while standing generally show sway to increase with age over adulthood. The studies of Sheldon (1963), Murray et al. (1975) and Hasselkus and Shambes (1975) were among the earliest to report this. More recently, Era and Heikkinen (1985) and Maki et al. (1990) confirmed that standing postural sway is more pronounced in the elderly, although the former authors found disturbed postural sway to be the same in young, middle-aged and old adults.

Reports of myoelectric responses to postural disturbances include those of Woollacott et al. (1986), Inglin and Woollacott (1988) and Manchester et al. (1989). Woollacott et al. (1986) found a statistically 
significant difference in the mean ankle muscle latencies between young and old adults, but this difference was only $7 \mathrm{~ms}$ in the approximately $100 \mathrm{~ms}$ latencies. The biomechanical significance of such small differences is unknown and the latency values vary, depending upon the methods used to determine them. Moreover, Manchester et al. (1989) found that during involuntary responses to postural disturbances, muscle latencies did not differ among the various age groups. Inglin and Woollacott (1988) found that when arm movements were carried out voluntarily while standing, lower-leg muscle response onset latencies were often significantly longer in old adults than in the young ones, and arm muscle response latencies showed even more pronounced age differences. Manchester et al. (1989) found that old adults used more antagonistic muscle contractions than the young ones during involuntary responses to postural disturbances, and that the sequence in which the leg muscles were contracted differed from that of young adults in five out of 12 old adults.

Few studies to date have analyzed in depth whole-body biomechanics or even body segment motions or joint torques developed in response to postural disturbances. Allum et al. (1988) and Manchester et al. (1989) made limited measurements indicative of ankle torques, and Horak and Nashner (1986) and Keshner et al. (1987) made limited measurements of body movements. Two more comprehensive studies of the motions and torques needed to maintain balance are those of Alexander et al. (1992) and Gu et al. (1992). The required motions and torques are generally modest compared to the literature-reported capacities of healthy old adults.

Bohannon et al. (1984) reported on the ability to balance for $30 \mathrm{~s}$ on one leg with eyes closed. They tested 184 healthy subjects between ages 20 and $79 \mathrm{yr}$. Every subject younger than $30 \mathrm{yr}$ could balance for at least $22 \mathrm{~s}$. No subject over $70 \mathrm{yr}$ could balance for more than $13 \mathrm{~s}$. It would be useful to learn why this occurs. Does it result from reduced ankle joint lateral bending muscle strength or endurance, increased muscle latency times, decreased cutaneous or joint proprioception, or decreased willingness to allow the center of the floor reaction to deviate from the centroid of the foot support area? These are some questions well suited to biomechanics inquiry. The answers to them are likely to be of fundamental importance in reducing problems of mobility impairment in the elderly.

\section{Gait}

In their pioneering studies of gait in the elderly, Murray et al. (1964) found that men in their sixties demonstrated significantly shorter step and stride lengths and decreased ankle extension and pelvic rotation compared to younger males. Murray et al. (1969) found that men 65-87 yr old, when compared to younger men, have significantly different stride lengths and cadence, and head, shoulder and ankle move- ments. More recent studies have confirmed many of these findings (Cunningham et al., 1982; Hageman and Blanke, 1986; Himann et al., 1988, for example), but not without exception. Blanke and Hageman (1989) found no significant differences in their age groups in step and stride length, velocity, and movements of the ankles, pelvis and total-body mass center. Gabell and Nayak (1984) concluded from their study that increased variability in gait should not be regarded as a normal concomitant of old age.

Cunningham et al. (1982) reported normal walking speed to be associated with the maximum aerobic power, independent of age. Bassey et al. (1988) found that the normal walking speed of elderly subjects significantly associates with their muscle strength, while Bendall et al. (1989) found that among elderly subjects more than $40 \%$ of the variance in the normal walking speed can be accounted for by differences in height, calf muccle strength and the presence of health problems such as leg pain. These various study outcomes are perhaps a good illustration of the effects of subject inclusion criteria on the outcome of studies of mobility problems in the elderly.

Difficulties in walking seem to relate to cognitive impairment. Visser (1983) found demented elderly patients to have a significantly shorter step length, step frequency, step-to-step variability and lower gait speed. Friedman et al. (1988) found that a geriatric rehabilitation program led to greater gains in the walking speed in subjects with normal cognition than in those with impaired cognition. Moreover, Friedman et al. found walking speed to be closely related to the ability to rise from a chair and a powerful predictor of patient placement upon discharge from the rehabilitation program. Of the 116 elderly subjects studied, none were able to live alone or even in a rest home if they were discharged with a walking speed below $0.15 \mathrm{~m} \mathrm{~s}^{-1}$.

The relationships between difficulties in walking and tendencies to fall are not yet clear. Wolfson $e t$ al. (1990) found stride length and walking speed to be significantly impaired in elderly fallers compared to controls, but Heitmann et al. (1989) found no corresponding significant differences in step width.

\section{Falls}

One of the most serious problems of mobility impairment is the tendency of old adults to fall. During a one-year prospective study of 336 community-dwelling persons 75 or more years old, $32 \%$ fell at least once. Of those who fell, $24 \%$ sustained serious injuries, and more than 5\% experienced fractures (Tinetti et al., 1988; Tinetti and Speechley, 1989). Among the elderly, falls account for $87 \%$ of all fractures (Fife and Barancik, 1985). Retrospective interviews found that $35 \%$ of 1042 communitydwelling persons 65 or more years old reported one or more falls in the preceding year (Blake et al., 1988). Death rates from falls per 100,000 persons in 1984 were 1.5 for those younger than 65 and 147.0 for those 


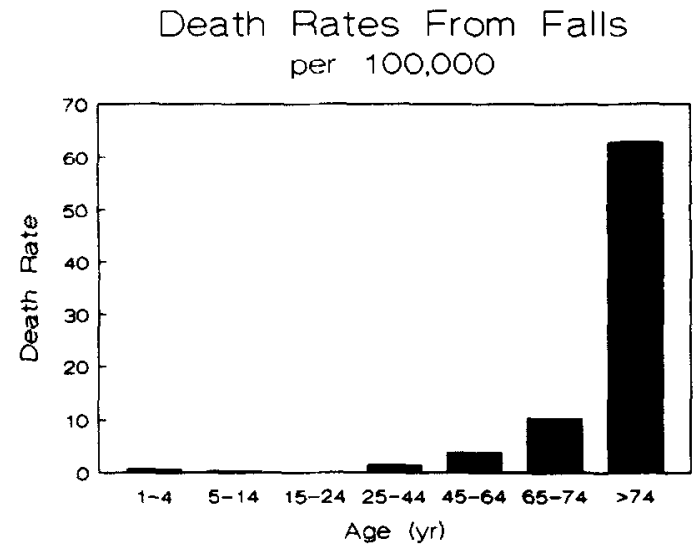

Fig. 4. Age effects in death rates per $10^{5}$ persons from falls. Data for 1984 (National Safety Council, 1987).

85 or more years old (Lambert and Sattin, 1988). Figure 4 illustrates age effects in fall death rates. The majority of falls in old people go unreported (Tideiksaar, 1988).

While the mechanisms related to increased falls in the elderly remain unclear, it was pointed out above that tendencies to fall and increases in postural sway while standing are related to each other. The elderly sway more than young adults while standing, as already noted, and elderly persons with a history of falls sway more while standing than elderly persons without such a history (Overstall et al., 1977; Fernie et al., 1982).

There is an urgent need for further studies of the biomechanics of maintaining standing posture and responding to fall-provoking stimuli. Why do old adults sway more and fall more often than young adults? Does the apparent motor response deterioration with age result from reduced muscular strengths and joint ROM, increased reaction times, inappropriatc body segment motion sequencing, or combinations of these or other mechanisms? Relatively little is known about these issues, and quantitative rather than qualitative studies would seem needed to arrive at an understanding of them.

\section{Bed and chair transfers}

It was pointed out above that almost $6 \%$ of, or over 1.6 million, non-institutionalized persons of ages $65 \mathrm{yr}$ and over have difficulty in getting in and out of beds and chairs. Four percent of non-institutionalized persons (Leon and Lair, 1990) and at least $54 \%$ of nursing home residents (Lair and Lefkowitz, 1990) over age $64 \mathrm{yr}$ need assistance in these transfer tasks. Dependency in transferring associates with an increased risk of institutionalization (Branch and Meyers, 1987) and immobility-related disease (Harper and Lyles, 1988).

Again, no matter what underlying mechanisms influence the transfer task abilities, these abilities are ultimately expressed in biomechanical terms. Biomechanical analyses of chair transfers, for example, can direct seating improvements and therapeutic interventions. More fundamentally, as emphasized earlier, biomechanical analyses of transfer task performance enable the effects of natural aging and illness on mobility impairment to be explored and help delineate the factors that are crucial to the maintenance of mobility.

Alexander et al. (1991) and Schultz et al. (1992) review previous studies of chair transfers. Most have involved only limited measurements of body kinematics, joint torques or myoelectric activities and few have included sizeable samples of elderly subjects. These two studies seem to be among the few that included elderly subjects who have difficulty in rising. More research on chair rise biomechanics is needed.

\section{Fractures and osteoporosis}

Fractures lead directly to mobility impairments. The alarming prevalence of hip fractures and the fact that this prevalence will virtually double over the next 30 years was pointed out in the Introduction. Moreover, at age 50 yr a white female has approximately a $15 \%$ lifetime risk of a Colles' fracture of her distal forearm. Five to $20 \%$ of $70 \mathrm{yr}$ old females have had fractures of their vertebrae (Cummings et al., 1985).

Cummings et al. (1985) review the literature on the relations between osteoporosis and fractures. It is well known that bone strength is highly correlated with bone mass and mineral content, and that bone mass declines with age over the adult years. Nevertheless, the literature suggests that while osteoporosis is the primary determinant of vertebral fractures, other factors are important in hip and Colles' fractures. Cummings et al. (1985) proposed that a combination of decreased bone mass and an increased frequency of trauma due to falls may combine to produce the pattern of increased risk of fractures with age. In a later paper, Cummings and Nevitt (1989) hypothesized that this combination alone does not explain the exponential rise of hip fracture incidence with age. They felt that several other changes in neuromuscular function with age, including changes in gait speed, reaction times and muscle strengths, may also be involved in the incidence of hip fractures.

Lotz and Hayes (1990) found that the work needed to fracture an isolated femur is only about onetwentieth of the kinetic energy developed in a typical fall. They suggest that the energy absorbed during falling and impact, rather than bone strength, is the dominant factor in the biomechanics of hip fracture. Cummings et al. (1985) remarked that prevention of falls in the elderly may be the most promising way to prevent fractures.

Exercise has often been advocated to prevent osteoporosis, but Block et al. (1989) concluded that exercise may have only limited value in its short-term effects on bone mass. The methodological flaws in the 27 studies on this issue that Block et al. reviewed have already been noted in the section on Muscle Function. 


\section{Arthritis}

Arthritis is relevant to mobility impairment in that it produces joint pain and limits joint ROM. Arthritis is the most prevalent chronic condition in persons older than $44 \mathrm{yr}$, occurring at rates of approximately 280 per 1000 persons in the 45-64 yr old group and 510 per 1000 persons in those older than 74 yr (Collins, 1988). The prevalence of osteoarthritis (OA) is clearly related to age. Roentgenographic evidence of OA was found in $4 \%$ of persons under age $24 \mathrm{yr}$, but up to $85 \%$ in persons 75-79 yr old (Moskowitz, 1987, citing earlier epidemiological studies). A cross-scctional study of 537 persons of age $79 \mathrm{yr}$ in Gothenburg, Sweden (Bergstrom et al., 1986) found radiographic evidence of OA in the wrist or hand of $65 \%$ and in the knee of $14 \%$. Symptoms of OA in the knee were found in approximately $7 \%$ and, in the hips, in approximately $6 \%$ of the above-cited population. Their study also found a $10 \%$ prevalence of rheumatoid arthritis.

\section{CLOSURE}

In its report, Year 2000 Objectives for the Nation, the Public Health Service (1989b) noted that there is wide variation between chronological and physiological age evident in the older population. A major research need is to 'understand aging processes and how aging is distinct from disease, in order to better understand the changes which are inevitable and open to modification'. This report called for ' . . a high priority ... to be placed on ... how to prevent disability.' This review has attempted to sketch the biomechanics research that should possibly be undertaken in order to help achieve that understanding and to learn how to prevent disability. To highlight some of its main ideas: physical disabilities ultimately express themselves as changes in the biomechanics of physical-task performance. Quantitative measures of mobility impairment are sorely needed because they can serve as indicators of subtle changes in the functioning over time. Perhaps the most important single goal for biomechanics research into mobility impairments in the elderly is to find what the critical elements of a mobility impairment are. The needs that have been outlined clearly constitute new and major challenges for biomechanics research.

Acknowledgements - The support of PHS Grants AG 06621 and AG 08818 and the Vennema Endowment for the preparation of this paper is gratefully acknowledged.

\section{REFERENCES}

Alexander, N. B., Gu, M. J., Schultz, A. B. and Shepard, N. B. (1992) Postural control in young and elderly adults when stance is perturbed: kinematics. J. Gerontol: Med. Sci. (in press).

Alexander, N. B., Schultz, A. B. and Warwick, D. N. (1991) Rising from a chair: effects of age and functional ability on performance biomechanics. J. Gerontol: Med. Sci. 46, M91-M98.
Allander, E., Bjornsson, O. J., Olafsson, O., Sigfusson, N. and Thorstensson, J. (1974) Normal range of joint movements in shoulder, hip, wrist and thumb with special reference to side: a comparison between two populations. Int. $J$. Epidemiol. 3, 253-261.

Allum, J. H. J., Keshner, E. A., Honegger, F. and Pfaltz, C. R. (1988) Organization of leg-trunk-head equilibrium movements in normal and patients with peripheral vestibular deficits. Prog. Brain Res. 76, 277-290.

Badley, E., Wagstaff, S. and Wood, P. H. N. (1984) Measures of functional ability (disability) in arthritis in relation to impairment of range of joint movement. Ann. Rheum. Dis. 43, 563-569.

Bassey, E. J., Bendall, M. J. and Pearson, M. (1988) Muscle strength in the triceps surae and objectively measured customary walking activity in men and women over 65 years of age. Clin. Sci. 74, 85-89.

Battie, M. C., Bigos, S. J., Sheehy, A. and Wortley, M. D. (1987) Spinal flexibility and individual factors that influence it. Phys. Ther. 67, 653-658.

Bendall, M. J., Bassey, E. J. and Pearson, M. B. (1989) Factors affecting walking speed of elderly people. Age and Ageing 18, 327-332.

Bergstrom, G., Aniansson, A., Bjelle, A., Grimby, G., Lundgren-Lindquist, B. and Svanborg, A. (1985a) Functional consequences of joint impairment at age 79. Scand. $J$. Rehab. Med. 17, 183-190.

Bergstrom, G., Bjelle, A., Sorensen, L. B., Sundh, V. and Svanborg, A. (1985b) Prevalence of symptoms and signs of joint impairment at age 79. Scand. J. Rehab. Med. 17, 173-182.

Bergstrom, G., Bjelle, A., Sorensen, L. B., Sundh, V. and Svanborg, A. (1986) Prevalence of rheumatoid arthritis, osteoarthritis, chondrocalcinosis and gouty arthritis at age 79. J. Rheumatol. 13, 527-534.

Blake, A. J., Morgan, K., Bendall, M. J., Dallosso, H., Ebrahim, S. B. J., Arie, T. H. D., Fentem, P. H. and Bassey, E. J. (1988) Falls by elderly people at home: prevalence and associated factors. Age and Aging 17, 365-372.

Blanke, D. J. and Hageman, P. A. (1989) Comparison of gait of young men and elderly men. Phys. Ther. 69 , $144 / 61-148 / 65$

Block, J. E., Smith, R., Friedlander, A. and Genant, H. K. (1989) Preventing osteoporosis with exercise: a review with emphasis on methodology. Med. Hypotheses 30, 9-19.

Bohannon, R. W., Larkin, P. A., Cook, A. C., Gear, J. and Singer, J. (1984) Decrease in timed balance test score with aging. Phys. Ther. 64, 1067-1070.

Boone, D. C. and Azen, S. P. (1979) Normal range of motion of joints in male subjects. J. Bone Jt Surg. 61A, 756-759.

Branch, L. G. and Meyers, A. R. (1987) Assessing physical function in the elderly. Clin. Geriatr. Med. 3, 29-51.

Burr, M. L. and Phillips, K. M. (1984) Anthropometric norms in the elderly. Br. J. Nutr. 51, 165-169.

Cathcart, E. P., Hughes, D. E. R. and Chalmers, J. G. (1935) The physique of man in industry. Medical Research Council Industrial Health Research Board, Report No. 71, pp. 1-43.

Chun, S. P., Alexander, N. B., Schultz, A. B. and AshtonMiller, J. A. (1992) Impending fall response biomechanics in young and old adults. J. Biomechanics (submitted).

Clarkson, P. M. (1978) The effect of age and activity level on simple and choice fractionated response time. Eur. J. appl. Physiol. 40, 17-25.

Collins, J. G. (1988) Prevalence of selected chronic conditions, United States, 1983-85. U.S. Department of Health and Human Services, Vol. 155, pp. 1-16.

Cummings, S. R., Kelsey, J. L., Nevitt, M. C. and O'Dowd, K. J. (1985) Epidemiology of osteoporosis and osteoporotic fractures. Epidemiol. Rev. 7, 178-208.

Cummings, S. R. and Nevitt, M. C. (1989) A hypothesis: the causes of hip fractures. J. Gerontol.: Med. Sci. 44, M107-M111.

Cunningham, D. A., Rechnitzer, P. A., Pearce, M. E. and 
Donner, A. P. (1982) Determinants of self-selected walking pace across ages 19 to 66. J. Gerontol. 37, 560-564.

Einkauf, D., Gohdes, M. L., Jensen, G. M. and Jewell, M. J. (1987) Changes in spinal mobility with increasing age in women. Phys. Ther. 67, 370-375.

Era, P. and Heikkinen, E. (1985) Postural sway during standing and unexpected disturbance of balance in random samples of men of different ages. J. Gerontol. 40. 287-295.

Era, P., Jokela, J. and Heikkinen, E. (1986) Reaction and movement times in men of different ages: a population study. Perceptual and Motor Skills 63, 111-130.

Faulkner, J., Brooks, S. V. and Zerba, E. (1990) Skeletal muscle weakness in old age: underlying mechanisms. Ann. Rev. Gerontol. Geriatr. 10, 147-166.

Feinstein, A. R., Josephy, B. R. and Wells, C. K. (1986) Review: scientific and clinical problems in indexes of functional disability. Ann. Int. Med. 105, 413-420.

Fernie, G. R., Gryfe, C. I., Holliday, P. J. and Llewellyn, A. (1982) The relationship of postural sway in standing to the incidence of falls in geriatric subjects. Age and Ayeing 11, 11-16.

Fife, D. and Barancik, J. I. (1985) Northeastern Ohio trauma study: III. Incidence of fractures. Ann. Emergency Med. 14, 244-248.

Friedman, P. J., Richmond, D. E. and Baskett, J. J. (1988) A prospective trial of serial gait speed as a measure of rehabilitation in the elderly. Age and Aging 17, 227-235.

Gabell, A. and Nayak, U. S. L. (1984) The effect of age on variability in gait. J. Gerontol. 39, 662-666.

Gorman, K. M. and Posner, J. D. (1988) Benefits of exercise in old age. Common Clinical Challenges in Geriatrics, pp. 181-192.

Gottsdanker, R. (1982) Age and simple reaction time. $J$. Gerontol. 37, 342-348.

Grimby, G, and Saltin, B. (1983) Review: the aging muscle. Clin. Physiol. 3, 209-218.

Gu, M. J., Schultz, A. B., Shepard, N. T. and Alexander, N. B. (1992) Postural control in young and elderly adults when stance is perturbed: dynamics. J. Biomechanics (submitted).

Guralnik, J. M., Branch, L. G., Cummings, S. R. and Curb, J. D. (1989) Review: physical performance measures in aging research. J. Gerontol. 44, M141-M146.

Hageman, P. A. and Blanke, D. J. (1986) Comparison of gait of young women and elderly women. Phys. Ther. 66, $1382-1387$.

Harper, C. M. and Lyles, Y. M. (1988) Physiology and complications of bed rest. J. Am. Geriatr. Soc. 36, 1047-1054.

Hasselkus, B. R. and Shambes, G. M. (1975) Aging and postural sway in women. J. Gerontol. 30, 661-667.

Heitmann, D. K., Gossman, M. R., Shaddeau, S. A. and Jackson, J. R. (1989) Balance performance and step width in noninstitutionalized, elderly, female fallers and nonfallers. Phys. Ther. 69, 923/43-931/51.

Himann, J. E., Cunningham, D. A., Rechnitzer, P. A. and Paterson, D. H. (1988) Age-related changes in speed of walking. Med. Sci. Sports Exercise 20, 161-166.

Horak, F. B. and Nashner, L. M. (1986) Central programming of postural movements: adaptation to altered support-surface configurations. J. Neurophysiol. 55, 1369-1381.

Horak, F. B., Shupert, C. L. and Mirka, A. (1989) Components of postural dyscontrol in the elderly: a review. Neurobiol. Aging 10, 727-738.

Inglin, B. and Woollacott, M. (1988) Age-related changes in anticipatory postural adjustments associated with arm movements. J. Gerontol. Med. Sci. 43, M105-M113.

Jette, A. M. and Branch, L. G. (1981) The Framingham disability study: II. Physical disability among the aging. AJPH 71, 1211-1216.

Jette, A. M. and Branch, L. G. (1985) Impairment and disability in the aged. $J$. Chronic Dis. 38, 59-65.
Kelly, P. L. and Kroemer, K. H. E. (1990) Anthropometry of the elderly: status and recommendations. Hum. Factors 32, 571-595.

Keshner, E. A., Allum, J. H. J. and Pfaltz, C. R. (1987) Postural coactivation and adaptation in sway stabilizing responses. Exp. Brain. Res. 69, 77-92.

Kokmen, E., Bossemeyer, R. W., Barney, J. and Williams, W. J. (1977) Neurological manifestations of aging. J. Gerontol. 32, 411-419.

Kokmen, E., Bossemeyer, R. W., Jr and Williams, W. J. (1978) Quantitative evaluation of joint motion sensation in an aging population. J. Gerontol. 33, 62-67.

Lair, T. and Lefkowitz, D. (1990) Mental health and functional status of residents of nursing and personal care homes. DHHS Publication No. PHS 90-3470, National Medical Expenditure Survey Research Findings, Vol. 7. Agency for Health Care Policy and Research, Rockville. MD.

Lambert, D. A. and Sattin, R. W. (1988) Deaths from falls, 1978-1984. MMWR CDC Surveill. Summ. 37, 21-26.

Ledin, T., Kronhed, A. C. and Moller, C. (1991) Effects of balance training in elderly evaluated by clinical tests and dynamic posturography. J. Vestib. Res. 1, 129-138.

Leon, J. and Lair, T. (1990) Functional status of the noninstitutionalized elderly: estimates of ADL and IADL difficulties. DHHS Publication No. PHS 90-3462, National Medical Expenditure Survey Research Findings, Vol. 4. Agency for Health Care Policy and Research, Rockville, MD.

Lotz, J. C. and Hayes, W. C. (1990) The use of quantitative computed tomography to estimate risk of fracture of the hip from falls. J. Bone $J t$ Surg. 72A, 689-700.

Maki, B. E., Holliday, P. J. and Fernie, G. R. (1990) Aging and postural control. A comparison of spontaneous- and induced-sway balance tests. J. Am. Geriatr. Soc. 38, 1-9.

Manchester, D., Woollacott, M., Zederbauer-Hylton, N. and Marin, O. (1989) Visual, vestibular and somatosensory contributions to balance control in the older adult. $J$ Gerontol. 44, M118-M127.

Moore, D. H. (1975) A study of age group track and field records to relate age and running speed. Nature $\mathbf{2 5 3}$, 264-265.

Moskowitz, R. W. (1987) Primary osteoarthritis: epidemiology, clinical aspects, and general management. $A m$. J. Med. 83, 5-10.

Murray, M. P., Drought, A. B. and Kory, R. C. (1964) Walking patterns of normal men. J. Bone Jt Surg. 46A, 335-360.

Murray, M. P., Kory, R. C. and Clarkson, B. H. (1969) Walking patterns in healthy old men. J. Gerontol. 24, 169-178.

Murray, M. P., Seireg, A. A. and Sepic, S. B. (1975) Normal postural stability and steadiness: quantitative assessment. $J$. Bone Jt Surg. 57A, 510-516.

National Safety Council (1987) Accident Facts. National Safety Council, Chicago.

Olshansky, S. J. and Ault, A. B. (1986) The fourth stage of the epidemiologic transition: the age of delayed degenerative diseases. Milbank Q. 64, 355-391.

Overstall, P. W., Exton-Smith, A. N., Imms, F. J. and Johnson, A. L. (1977) Falls in the elderly related to postural imbalance. Br. Med. J. 1, 261-264.

Potvin, A. R., Tourtellotte, W. W., Syndulko, K. and Potvin, J. (1981) Quantitative methods in assessment of neurologic function. CRC Crit. Rev. Bioengng 6, 177-224.

Public Health Service (1989a) Health United States 1988 U.S. Department of Health and Human Services, DHHS Pub. PHS 89-1232.

Public Health Service (1989b) Promoting health/preventing disease: year 2000 objectives for the nation. U.S. Department of Health and Human Services.

Quetelet, L. A. J. (1835) Sur Thomme et le developpement de ses facultes. (Edited by Hauman, L. and Cie), Vol. 2. Bachelier, Imprimeur-Librairie: Paris. 
Roaas, A. and Andersson, G. B. J. (1982) Normal range of motion of the hip, knee and ankle joints in male subjects, $30-40$ years of age. Acta orthop. scand. 53, 205-208.

Rogers, M. and Chan, C. W. Y. (1988) Motor planning is impaired in Parkinson's disease. Brain Res. 438, 271-276.

Salthouse, T. A. (1985) Speed of behavior and its implications for cognition. In Handbook of the Psychology of Aging (Edited by Birren, J. E. and Schaie, K. W.), pp. 400-426. Van Nostrand Reinhold, New York.

Schneider, E. L. and Guralnik, J. M. (1990) The aging of America-impact on health care costs. JAMA 263, 2335-2340.

Schultz, A. B., Alexander, N. B. and Ashton-Miller, J. A. (1992) Biomechanical analyses of rising from a chair. J. Biomechanics (submitted).

Sheldon, J. H. (1963) The effect of age on the control of sway. Geront. Clin. 5, 129-138.

Shepard, R. J. (1990) The scientific basis of exercise prescribing for the very old. J. Am. Geriatr. Soc. 38, 62-70.

Shimokata, H., Andres, R., Coon, P. J., Elahi, D., Muller, D. C. and Tobin, J. D. (1989) Studies in the distribution of body fat. II. Longitudinal effects of change in weight. Int. J. Obes. 13, 455-464.

Skinner, H. B., Barrack, R. L. and Cook, S. D. (1984) Agerelated decline in proprioception. Clin. Orthop. Rel. Res. 184, 208-211.

Stelmach, G. E. and Worringham, C. J. (1985). Sensorimotor deficits related to postural stability. Implications for falling in the elderly. Clin. Geriatr. Med. 1, 679-694.

Stoudt, H. (1981) The anthropometry of the elderly. Hum. Factors 23, 29-37.

Svanborg, A. (1988) Practical and functional consequences of aging. Gerontology 34, 11-15.

Tideiksaar, R. (1988) Falls in the elderly. Bull. N.Y. Acad. Med. 64, 145-163.

Tinetti, M. E. (1986) Performance-oriented assessment of mobility problems in elderly patients. J. Am. Geriatr. Soc. 34, 119-126.
Tinetti, M. E. and Ginter, S. F. (1988) Identifying mobility dysfunctions in elderly patients--standard neuromuscular examination or direct assessment? JAMA 259, 1190-1193.

Tinetti, M. E. and Speechley, M. (1989) Prevention of falls among the elderly. N. Engl. J. Med. 320, 1055-1059.

Tinetti, M. E., Speechley, M. and Ginter, S. F. (1988) Risk factors for falls among elderly persons living in the community. N. Engl. J. Med. 319, 1701-1707.

Vandervoort, A. A., Dramer, J. F. and Wharram, E. R. (1990) Eccentric knee strength of elderly females. J. Gerontol.: Biol. Sci. 45, B125-B128.

Viitisalo, J. T., Era, P., Leskinen, L. and Heikkinen, E. (1985) Muscular strength profiles and anthropometry in random samples. Ergonomics 28, 1563-1574.

Visser, H. (1983) Gait and balance in senile dementia of Alzheimer's type. Age and Ageing 12, 296-301.

Walker, J. M., Sue, D., Miles-Elkousy, N., Ford, G. and Trevelyan, H. (1984) Active mobility of the extremities in older subjects. Phys. Ther. 64, 919-923.

Ward, J. S. and Kirk, N. S. (1967) Anthropometry of elderly women. Ergonomics 10, 17-24.

Welford, A. T. (1984) Between bodily changes and performance: some possible reasons for slowing with age. Exp. Aging Res. 10, 73-88.

Welford, A. T. (1988) Reaction time, speed of performance, and age. Ann. N.Y. Acad. Sci. 515, 1-17.

Winter, D. A., Patla, A. E. and Frank, J. S. (1990) Assessment of balance control in humans. Med. Prog. Technol. 16, 31-51.

Wolfson, L., Whipple, R., Amerman, P. and Tobin, J. N. (1990) Gait assessment in the elderly: a gait abnormality rating scale and its relation to falls. J. Gerontol: Med. Sci. 45, M12-M19.

Woollacott, M. H., Shumway-Cook, A. and Nashner, L. M. (1986) Aging and postural control: changes in sensory organization and muscular coordination. Int. J. Aging Hum. Develop. 23, 97-114. 